\title{
Self-organized criticality of developing artificial neuronal networks and dissociated cell cultures
}

\author{
Christian Tetzlaff*1, Samora Okujeni ${ }^{2}$, Ulrich Egert ${ }^{2}$, Florentin Wörgötter ${ }^{1}$ \\ and Markus Butz ${ }^{1,3}$
}

\author{
Address: ${ }^{B}$ BCCN Göttingen, Georg-August University, Göttingen, 37075, Germany, ${ }^{2 B C C N}$ Fribourg, Albert-Ludwigs University, Fribourg, 79110 , \\ Germany and ${ }^{3}$ Dept. for Integrative Neurophysiology, VU University, Amsterdam, 1081, Netherlands \\ Email: Christian Tetzlaff* - tetze@nld.ds.mpg.de \\ * Corresponding author
}

from Eighteenth Annual Computational Neuroscience Meeting: CNS*2009

Berlin, Germany. 18-23 July 2009

Published: I 3 July 2009

BMC Neuroscience 2009, I0(Suppl I):P2I5 doi:I0.1I86/I47|-2202-I0-SI-P2I5

This abstract is available from: http://www.biomedcentral.com/I47|-2202/I0/SI/P2 I5

(C) 2009 Tetzlaff et al; licensee BioMed Central Ltd.

Self-organized criticality (SOC) [1] was first described in neuronal cell cultures by Beggs and Plenz [2]. Neuronal networks being in a critical state produce avalanche-like discharges that are power-law distributed. The assessment of avalanches in neuronal networks is a new way of looking at neuronal activities apart from bursts, synchronization etc. The main novelty of our approach is to assess the avalanche distribution at different developmental stages of neuronal networks. For this, we used dissociated postnatal cell culture taken from the rat cortex. Experimental data was provided by the Ulrich Egert group, BCCN Fribourg, Germany. We found that different network states as subcritical, critical or supracritical specify a time and spatial activity profile that is linked but not equivalent to low, moderate or high levels in neuronal activity, respectively. We are the first who show that the activity profile in cell cultures develop from supracritical states over subcritical into critical states. To shed light to the dependency of SOC on network development, we used a self-organizing artificial neuronal network model based on a previous model by Van Ooyen and Abbott [3-5]. An important novelty of our model is that it is more detailed with respect to representing seperate axonal and dendritic fields $[6,7]$. The model network aims to develop towards a homeostatic equilibrium in neuronal activity that is achieved by growth and retraction of axonal and dendritic fields. This abstract model already reproduces the transient behavior as seen in cell cultures from supracritical over subcritical to critical states. However, we found that some cell cultures remain in a subcritical regime. The model offers a simple explanation as depending on the strength of inhibition, equivalent to the friction in selforganizing systems [8], neuronal networks may or may not reach criticality even though they are homeostatically equilibrated.

\section{References}

I. Bak P, Tang C, Wiesenfeld K: Self-organized criticality: An explanation of I/f-noise. Phys Rev Lett 1987, 59:38I-384.

2. Beggs J, Plenz D: Neuronal avalanches in neocortical circuits. J Neurosci 2003, 23: I II67-III77.

3. Van Ooyen A, Van Pelt J: Activity-dependent outgrowth of neurons and overshoot phenomena in developing neural networks. J Theor Biol 1994, 167:27-43.

4. Van Ooyen A, Van Pelt J, Corner M: Implications of activitydependent neurite outgrowth for neuronal morphology and network development. J Theor Biol 1995, 172:63-82.

5. Abbott L, Rohrkemper R: A single growth model constructs critical avalanche networks. Prog Brain Res 2007, 165:9.

6. Butz M, Teuchert-Noodt G, Grafen K, Van Ooyen A: Inverse relationship between adult hippocampal cell proliferation and synaptic rewiring in the dentate gyrus. Hippocampus 2008, 1 8:879-898.

7. Butz M, Wörgötter F, Van Ooyen A: Activity-dependent structural plasticity. Brain Res Rev 2009. doi:10.1016/j.brainresrev.2008.12.023

8. Lauritsen K, Zapperi S, Stanley H: Self-organized branching process: Avalanche models with dissipation. Phys Rev E 1996, 54:2483-2488. 